\title{
Solvation dynamics of coumarin 153 in mixtures of carbon dioxide and room temperature ionic liquids
}

\author{
$\operatorname{AUTHOR}(S)$ : \\ Kimura, Yoshifumi; Kobayashi, Akira; Demizu, \\ Masashi; Terazima, Masahide
}

\section{CITATION:}

Kimura, Yoshifumi ...[et al]. Solvation dynamics of coumarin 153 in mixtures of carbon dioxide and room temperature ionic liquids. Chemical Physics Letters 2011, 513(1-3): 5358

\section{ISSUE DATE:}

2011-09

URL:

http://hdl.handle.net/2433/147321

\section{RIGHT:}

(C) 2011 Elsevier B.V.; This is not the published version. Please cite only the published version.; この論文は出版社版でありません。引用の際に は出版社版をご確認ご利用ください。 
Solvation dynamics of coumarin 153 in mixtures of carbon dioxide and room temperature ionic liquids

Yoshifumi Kimura*, Akira Kobayashi, Masashi Demizu, and Masahide Terazima

Department of Chemistry, Graduate School of Science, Kyoto University, Kyoto 606-8502, Japan

Corresponding author

Y. Kimura

Department of Chemistry, Graduate School of Science, Kyoto University, Kyoto 606-8502, Japan

Email: ykimura@kuchem.kyoto-u.ac.jp

TEL: +81-75-753-4024

FAX: $+81-75-753-4000$ 


\begin{abstract}
Effects of dissolved carbon dioxide $\left(\mathrm{CO}_{2}\right)$ on the solvation dynamics of coumarin 153 were studied in 1-butyl-3-methylimidazolium hexafluorophosphate, and 1-butyl-3-methylimidazolium bis(trifluoromethanesulfonyl)amide by the time resolved fluorescence spectroscopy. The solvation dynamics showed an ultrafast response less than 1 ps and a slower response extended to a half of ns under ambient condition. With increasing the $\mathrm{CO}_{2}$ pressure, the slower component became fast, although no significant change was observed for the faster component. The $\mathrm{CO}_{2}$ effect on the average solvation time was compared with that on the translational diffusion of the solute molecule dissolved in the mixture.
\end{abstract}




\section{Introduction}

It has been known that several room temperature ionic liquids (RTILs) dissolve carbon dioxide $\left(\mathrm{CO}_{2}\right)$ significantly at high $\mathrm{CO}_{2}$ pressures, and the phase behavior and the structure of the solution have been extensively studied experimentally and theoretically until now[1-13]. By dissolving $\mathrm{CO}_{2}$, the transport properties of RTILs are also significantly modified[14-16]. Previously we have reported that the translational diffusion coefficients of solute molecules, carbon monoxide (CO), diphenylacetylene (DPA), and diphenylcyclopropenone (DPCP) dissolved in 1-butyl-3-methylimidazolium ([BMIm]) cation based ILs increased nearly one order of magnitude by applying the $\mathrm{CO}_{2}$ pressure to $10 \mathrm{MPa}[15,16]$. On the other hand, the solute-solvent interaction monitored by the Raman shift of the $\mathrm{C}=\mathrm{O}+\mathrm{C}=\mathrm{C}$ stretching mode of DPCP was hardly modified by dissolved $\mathrm{CO}_{2}$ [16], which was consistent with the preceding report of the $\mathrm{CO}_{2}$ effect on the solvatochromic shift[17]. It is quite an interesting issue why the solute dynamics is significantly modified by $\mathrm{CO}_{2}$ although the solute-solvent interaction hardly changes. In this sense, the study on the solvent dynamics around the solute molecule will bring a new insight into the effect of $\mathrm{CO}_{2}$ on the solvation. In this letter, we report the effect of $\mathrm{CO}_{2}$ on the solvation dynamics in RTILs for the first time to our best knowledge.

The solvation dynamics of RTILs has been widely investigated, and characteristic features of the solvation dynamics have been clarified[18-28]. Arzhantsev et al. reported the complete solvation dynamics from a sub-picosecond time range to a nanoseconds range using the time-resolved fluorescence measurement of 4-dimethylamino-4'-cyanostilbene (DCS) by the combination of an optical Kerr gate method and a time correlated photon-counting 
technique[20,25]. They have reported that there is a very fast time response, e.g. $330 \mathrm{fs}$ in 1-butyl-3methylimidazolium hexafluorophosphate $\left([\mathrm{BMIm}]\left[\mathrm{PF}_{6}\right]\right)$, together with slower dynamics extended to $1 \mathrm{~ns}$. Recently Kimura et al. also reported the complete solvation dynamics using another probe molecule, 4'-N,N-diethylamino-3-methoxyflavone (DEAHF), and observed similar behaviors of the solvation dynamics in various RTILs[29]. The fast part of the solvation dynamics was often assigned to the inertial movement of the solvent cation and anion[26,30], although recent theoretical model calculation based molecular hydrodynamics using the dielectric spectrum of RTILs suggests that the dipole-dipole interaction between the imidazolium cation and the solute molecule is responsible for the ultrafast relaxation[31-33]. The slower part was generally suggested to reflect the translational diffusional motion of the cation and anion and related to the viscosity of RTILs.

In this paper, we used coumarin $153(\mathrm{C} 153)$ to probe the solvation dynamics. C153 is one of the most popular fluorescent probes used for the study of the solvation dynamics, and the solvation dynamics using C153 in RTILs have already been studied by many researchers[18,20,21,23,25,27]. Jin et al. studied the solvation dynamics of C153 in varieties of RTILs and found that there is a good linear correlation between the average solvation time (excluding the ultrafast response) and the solvent viscosity[27]. In this work, with a combination of the optical Kerr gate method and the streak camera measurement, we studied the solvation dynamics of C153 in two RTILs, 1-butyl-3-methylimidazolium

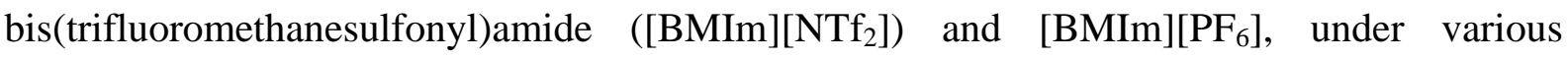
pressures of $\mathrm{CO}_{2}$ (see Scheme 1). The solvation time will be discussed in relation with the 
change of the solvation structure and the translational diffusion of the solute molecule.

\section{Experimental}

The experimental setups for the fluorescence measurements using an optical Kerr gate method and a streak camera have been described elsewhere[29]. Briefly, the second harmonic pulse $(400 \mathrm{~nm})$ from an amplified Ti: sapphire laser system (Spectra Physics, Spitfire ProXP) was used for the excitation pulse. For the optical Kerr gate measurement, the fluorescence from the sample was collected and focused into the Kerr media (benzene) by a combination of the parabolic mirror and a concave lens. The fundamental output from the laser system $(800 \mathrm{~nm})$ was used as the gate pulse, and the Kerr gated fluorescence was detected by an intensified CCD camera (ICCD) equipped with a spectrometer. The corrections for the color sensitivity, the wavelength dependence of the time response due to GVD, and the re-absorption of the fluorescence by the sample have been done as mentioned previously[29]. The FWHM of the system response function estimated from the fluorescence rise time of $\mathrm{C} 153$ in cyclohexane was ca. $0.8 \mathrm{ps,}$, which was relatively longer than that in the previous work[29] because of the longer optical path using the high pressure cell. For the measurement in a longer time range (more than hundred ps), the fluorescence was detected by a streak camera (Hamamatsu, C4334). In both measurements, the polarization of the excitation pulse was set to a magic angle in order to remove the effect of orientation relaxation.

The high pressure cell and other high pressure equipment used for the measurement 
have been described elsewhere[34]. The cell had two optical windows with a wide aperture which enabled an efficient collection of fluorescence from the sample. The optical path length was $4 \mathrm{~mm}$. The temperature of the sample was kept to $40{ }^{\circ} \mathrm{C}$ with the thermo-controlled water flowing through the water path inside the cell. Compressed $\mathrm{CO}_{2}$ was supplied by a HPLC pump (JASC SCF-Get) and stored in a reservoir for the use. In the measurement, $\mathrm{CO}_{2}$ from the reservoir was introduced into the high pressure cell containing the sample solution. The pressure of the cell was monitored by a strain gauge (Kyowa PGM-500KH). A series of the experiment in each IL was performed in the following way: firstly the time-resolved fluorescence was measured under ambient pressure at $40{ }^{\circ} \mathrm{C}$ for the sample solution enclosed in the high pressure cell. Then $\mathrm{CO}_{2}$ was introduced into the cell up to ca. $20 \mathrm{MPa}$. After the equilibrium was attained and the pressure of the system was stabilized, the measurement was performed at the pressure. Then the pressure of the system was slowly decreased to the next pressure for the measurement. After the equilibrium achievement (ca. 3 hours), the measurement was performed. This cycle was repeated to reach the atmospheric pressure.

$[\mathrm{BMIm}]\left[\mathrm{NTf}_{2}\right]$ and $[\mathrm{BMIm}]\left[\mathrm{PF}_{6}\right]$ were purchased from Kanto Kagaku. These ionic liquids were transparent at $400 \mathrm{~nm}$ and no detectable fluorescence was emitted at $400 \mathrm{~nm}$ excitation. In the sample preparation, the absorbance of Coumarin 153 in the solution was adjusted to be around 1.0 at $400 \mathrm{~nm}$ for the $4 \mathrm{~mm}$ optical path length. Before the measurement, the sample solution was evacuated for more than 10 hour at $60{ }^{\circ} \mathrm{C}$ in order to remove volatile impurities such as water. The water contents were checked by the Karl 
Fisher moisture titration (MKC-501, Kyoto Electronics Manufacturing Co. Ltd.). They were less than $100 \mathrm{ppm}$ before the measurement, and it increased by 100 to $200 \mathrm{ppm}$ after the measurement.

\section{Results}

Figure 1 shows the time-resolved fluorescence spectra in $\left[\mathrm{BMIm}^{2}\left[\mathrm{PF}_{6}\right]\right.$ at $9 \mathrm{MPa}$ pressure of $\mathrm{CO}_{2}$. The spectra from 0 ps to 180 ps shown in Figure 1 were obtained by the Kerr gate method and the later ones by the streak camera. The spectra showed a red-shift with time indicating the existence of the solvation dynamics. In order to extract the peak position at each delay time, each fluorescence spectrum was fit to a log-normal function as

$$
F(t, v)=h(t) \times\left\{\begin{array}{cc}
\exp \left[-\ln (2)\left\{\ln \left(1+2 \gamma\left(v-v_{p}(t)\right) / \Delta(t)\right) / \gamma(t)\right\}^{2}\right] & 2 \gamma\left(v-v_{p}(t)\right) / \Delta(t)>-1 \\
0 & 2 \gamma\left(v-v_{p}(t)\right) / \Delta(t) \leq-1
\end{array}\right.
$$

where $F(t, v)$ is the fluorescence intensity at the delay time $t, h(t)$ the scaling factor, $v_{\mathrm{P}}(t)$ the peak position, $\gamma(t)$ the asymmetric parameter, and $\Delta(\mathrm{t})$ the band width parameter, respectively, and these parameters were assumed to be dependent on time $t$. In the fitting procedure, at first, the spectrum at the longest delayed time within the measured time range was simulated by Eq. (1), and then the spectrum at the earlier delay time was fit by using the parameters determined by the previous fit as the initial guess for the fitting. The solid lines in the figure show the results of the fitting, and the function simulates the fluorescence spectrum well.

Figure 2 shows examples of the time profile of the peak positions of the fluorescence 
spectra determined by the fit. In the figure we plotted both results from the optical Kerr gate measurement and the streak camera measurement. In some cases, there was a systematic difference of the peak positions determined by two methods (ca. $50 \mathrm{~cm}^{-1}$ ) even at the same delay time. In such a case, the peak positions determined by the streak camera measurements were artificially shifted to match the peak positions determined by the optical Kerr gate measurements. The time profile of the peak position was simulated by the sum of a single exponential function less than 1 ps lifetime $\left(\tau_{1}\right)$ and a stretched exponential function with lifetime $\tau_{2}$ and exponent $\beta$ as[26, 27]

$v_{P}(t)=v_{\infty}+\Delta v_{1} \exp \left(-\left(t / \tau_{1}\right)\right)+\Delta v_{2} \exp \left(-\left(t / \tau_{2}\right)^{\beta}\right)$

where $v_{\infty}, \Delta v_{1}$, and $\Delta v_{2}$ are the peak position at the time infinite, and peak shifts due to the first and slow components, respectively. At first, we fit the result assuming that all parameters are adjustable. However, we found that the value of $\beta$ was hardly dependent on the $\mathrm{CO}_{2}$ pressure within our experimental errors. Therefore, we fit the time profile of the peak position by fixing the value of $\beta$ as 0.50 for $[\mathrm{BMIm}]\left[\mathrm{NTf}_{2}\right]$ and 0.55 for $[\mathrm{BMIm}]\left[\mathrm{PF}_{6}\right]$, where these values were determined by the averages of the fit with $\beta$ as an adjustable parameter (the value of $\beta$ had the variation of ca. $5 \%$ of the value). The results of the fit to Eq. (2) are shown by black solid lines in Figure 2, which traced the experimental results fairly well, although a slight deviation was found for the longer delay data in the case of $[\mathrm{BMIm}]\left[\mathrm{NTf}_{2}\right]$. The parameters obtained by the signal fitting are summarized in Table 1 and 2. The molar fraction of $\mathrm{CO}_{2}$ in the mixture $\left(\mathrm{X}_{\mathrm{CO} 2}\right)$ was calculated from the pressure using the data in the literature[4]. In the table, the average solvation time $\left(\left\langle\tau_{S}\right\rangle=\tau_{2} \Gamma\left(\beta^{-1}\right) / \beta\right.$, 
where $\Gamma(\xi)$ is a gamma function of $\xi$ ) obtained by the integral of the stretched exponential part only is also listed. In this paper, we mean the integration of the slower part neglecting the fast response by the "average" solvation time. The average solvation time was determined with uncertainty of less than $15 \%$ of the value, considering the uncertainty of $\beta$ and variations of the values with different experimental runs.

\section{Discussions}

Before the discussion on the solvation dynamics, we will mention how the solvatochromic shift and fluorescence Stokes shift are modified by the presence of $\mathrm{CO}_{2}$. The solvatochromic shift of C153 mainly reflects the dipole-dipole interaction between solute and solvent just like the $\pi^{*}$ value. As is shown in Tables 1 and 2 , the peak positions of the fluorescence at the time infinite are almost independent of the $\mathrm{CO}_{2}$ pressure within the accuracy of our measurement. This is the same trend as observed for the $\pi^{*}$ values previously[17]. The fluorescence Stokes shift $\left(v_{a b s}-v_{\infty}\right)$ did not show significant dependence on $\mathrm{X}_{\mathrm{CO} 2}$ either. The fluorescence Stokes shift reflects the sum of the intramolecular reorganization energy and the solvent reorganization energy upon photo-excitation. Our result suggests that both reorganization energies are not strongly dependent on $\mathrm{X}_{\mathrm{CO} 2}$. Therefore it is confirmed that the presence of $\mathrm{CO}_{2}$ does not affect the solvation energy and its fluctuation from the surrounding cation and anion molecules, as suggested previously[16,17].

As is shown in Table 1 and 2, the dependence of the faster solvation time on $\mathrm{X}_{\mathrm{CO} 2}$ was minor. It is noted here that the relative magnitude of the ultrafast component to the total 
solvation is rather larger (ca. 30\%) than the other cases such as DCS (ca. $10 \sim 20 \%$ ) [26] and DEAHF (ca. $8 \sim 15 \%$ ) [29]. The ultrafast solvation time is often suggested to be related to the inertial motions of cation and anion [26]. Since the mass of $\mathrm{CO}_{2}$ is rather light than those of cation and anion, the existence of $\mathrm{CO}_{2}$ may not interfere the inertial movement of these molecules. Recent theoretical calculation based on the molecular hydrodynamics using the dielectric spectrum of RTILs, on the other hand, suggests that the dipole-dipole interaction between the imidazolium cation and solute molecule is responsible for the fast response. The origin of the fast response is still in debate, and therefore the detail should be discussed after getting further information such as the dielectric spectra of the mixture, and more reliable data on the fast solvation time for the mixture. The FWHM of our system response function estimated by the rise of the fluorescence was ca. $0.8 \mathrm{ps}$, and the time-resolution was not enough to fully resolve the initial fast dynamics. We will not discuss the detail of the $\mathrm{CO}_{2}$ effect on the fast solvation part further in this paper.

In Figure 3, the average solvation time is plotted against the pressure. The average solvation time became dramatically faster with increasing the $\mathrm{CO}_{2}$ pressure. In the case of $[\mathrm{BMIm}]\left[\mathrm{PF}_{6}\right]$, the average solvation time at $3 \mathrm{MPa}$ was nearly one-thirds of the value under ambient condition. At the higher pressure of $\mathrm{CO}_{2}$ the change became small. Further, the solvation time seems to be slower with increasing the pressure more than ca. $10 \mathrm{MPa}$. In the case of $[\mathrm{BMIm}]\left[\mathrm{NTf}_{2}\right]$, the average solvation time at $20 \mathrm{MPa}$ is apparently slower than that 9MPa. It is to be noted here that the sound velocity of the mixture showed similar pressure dependence [16]: i.e., the sound velocity dramatically decreased with increasing the $\mathrm{CO}_{2}$ 
pressure up to ca. $10 \mathrm{MPa}$, then it turned to increase slightly with further increase of the pressure. As was discussed previously [16], the sound velocity is related to the isentropic compressibility, and the change of the response may be related to the structure hardness of the mixture.

In previous works under ambient conditions [26,27], the average solvation time has often been compared with the viscosity of the solvent. Jin et al. found a good correlation between the solvent viscosity and the average solvent correlation time for C153 in various RTILs at various temperatures[27]. Unfortunately viscosity data of mixtures of RTILs and $\mathrm{CO}_{2}$ are quite limited. For the systems under investigation, the viscosity of $[\mathrm{BMIm}]\left[\mathrm{PF}_{6}\right]$ with $\mathrm{CO}_{2}$ was reported[35]. However, the ionic liquid used in this report was contaminated by water $(0.1 \mathrm{wt} \%)$, and the reported value under ambient condition was rather smaller $(92.3$ $\mathrm{mPa}$ s) than those of other reports[36,37] (e.g., $120 \mathrm{mPa} \mathrm{s}$ in ref.[36]). Therefore it is difficult to compare our solvation time with the viscosity of the mixture. Figure 4 compares the average solvation time reported in various RTILs with those of this work against the solvent viscosity. We plotted the results only under ambient pressure. As is shown in the figure, our values almost lie on the correlation previously obtained, although our data are somewhat faster than the previous reports if compared at the same solvent viscosity. At present, we do not have clear explanation of the difference. This point should be examined in the future together with the viscosity data for the mixture.

Finally we compare the average solvation time with the diffusion coefficients of the solvent molecules under the same thermodynamics condition. Previously we have studied 
the diffusion coefficients of CO, DPA, and DPCP in several RTILs under the $\mathrm{CO}_{2}$ pressure[15,16]. We found that the diffusion coefficients significantly increases with increasing the $\mathrm{CO}_{2}$ pressure, and the effect of the $\mathrm{CO}_{2}$ pressure was dependent on the size of the solute molecule; the diffusion of the larger solute molecule is more significantly affected by the presence of $\mathrm{CO}_{2}$. According to the fluctuation-dissipation theorem, the inverse of the diffusion coefficient is related to the friction acting on the solvent molecules, and therefore related to the solvent viscosity. On the other hand, the slower part of the solvation dynamics is correlated with the solvent viscosity as is mentioned in the previous paragraph[27]. Therefore it is interesting to compare the $\mathrm{CO}_{2}$ dependence of these two values and to see how differently the solvent effects appear in these values.

Although it is desirable to compare the average solvation time with the inverse of the diffusion coefficient of $\mathrm{C} 153$, the diffusion coefficient $\mathrm{C} 153$ is not available now. Here we compared the inverse of the diffusion coefficient of DPCP with the solvation dynamics of C153 in Figure 5. The dependence on $\mathrm{X}_{\mathrm{CO} 2}$ is quite similar to each other in both RTILs: i.e. the effect is larger in the smaller $\mathrm{X}_{\mathrm{CO} 2}$ region, and the effect is gradually saturated in the larger $\mathrm{X}_{\mathrm{CO} 2}$ region. Therefore the solvent movement which dominates the solvation dynamics is related to the solvent dynamics which dominates the solute diffusion. It is noteworthy that in the case of the translational diffusion we did not see the inversion of the pressure effect at the very higher $\mathrm{CO}_{2}$ molar fraction in contrast to the case of the average solvation time. As a result, the $\mathrm{CO}_{2}$ effect is apparently more significant for the translational diffusion at the higher pressure. We are not sure of the reason why the response to the $\mathrm{CO}_{2}$ pressure is 
different at the higher pressure region. Recently, Yamaguchi et al. measured frequency-dependent shear viscosity and showed that shear relaxation of RTILs occurs slowly from several hundred $\mathrm{MHz}$ (several hundred picoseconds to several nanoseconds)[38]. Since the translational diffusion is slower dynamics than the solvation dynamics observed here, the difference of the memory scale may result in the different response to the applied $\mathrm{CO}_{2}$ at the higher pressure.

\section{Conclusion}

In this letter, we have reported the solvation dynamics of C153 in the mixtures of $\mathrm{CO}_{2}$ and RTILs for the first time. Although the strength of the solute-solvent dipolar interaction and its fluctuation estimated from the solvatochromic shift and the fluorescence Stokes shift are hardly dependent on the $\mathrm{CO}_{2}$ pressure, it is found that the solvation dynamics is strongly affected by the presence of $\mathrm{CO}_{2}$. The solvation dynamics is divided into two different components; the faster one is expressed by a single exponential function with a time constant of $<1 \mathrm{ps,}$ and the slower one expressed by a stretched exponential function. Although the faster component does not show a meaningful pressure effect, the slower component becomes significantly faster with increasing the mole fraction of $\mathrm{CO}_{2}$. The effect of $\mathrm{CO}_{2}$ on the slower solvation dynamics is found to be similar to those of the inverse of the translational diffusion coefficients of the solute molecules dissolved in the mixture. In the future, it is expected to connect the structural variation and the dynamical effect of the $\mathrm{CO}_{2}$ mixture. 


\section{Acknowledgement}

This work is supported by the Grant-in-Aid for Scientific Research (No. 17073012 and No.

23655144) from the Ministry of Education, Culture, Sports, Science, and Technology. This work is also partially supported by Core-Stage program from Kyoto University. 


\section{References}

${ }^{1}$ L. A. Blanchard, D. Hancu, E. J. Beckman, J. F. Brennecke, Nature, 399 (1999) 28.

2 S. G. Kazarian, B. J. Briscoe, T. Welton, Chem. Comm. (2000) 2047.

${ }^{3}$ L. A. Blanchard, Z. Gu, J. F. Brennecke, J. Phys. Chem. B 105 (2001) 2437.

${ }^{4}$ S. N. V. K. Aki, B. R. Mellein, E. M. Saurer, J. F. Brennecke, J. Phys. Chem. B 108 (2004) 20355.

${ }^{5}$ C. Cadena, J. L. Anthony, J. K. Shah, T. I. Morrow, J. F. Brennecke, E. J. Maginn, J. Am. Chem. Soc. 126 (2004) 5300.

${ }^{6}$ M. Kanakubo, T. Umecky, Y. Hiejima, T. Aizawa, H. Nanjo, Y. Kameda, J. Phys. Chem. B 109 (2005) 13847.

7 X. Huang, C. J. Margulis, Y. Li, B. J. Berne, J. Am. Chem. Soc. 127 (2005) 17842.

8 B. L. Bhargava, S. Balasunramanian, J. Phys. Chem. B 111 (2007) 4477.

${ }^{9}$ B. L. Bhargava, A. C. Krishna, and S. Balasubramanian, AIChE J. 54 (2008) 2971.

10 T. Seki, J.-D. Grunwaldt, A. Baiker, J. Phys. Chem. B 113 (2009) 114.

11 J. M. Andanson F. Jutz, A. Baiker, J. Phys. Chem. B 113 (2009) 10246.

12 J. Huang, T. Rüther, Aust. J. Chem. 62 (2009) 298.

13 T. Makino, J. Phys. Conf. Ser. 215 (2010) 012068.

${ }^{14}$ M. Kanakubo, T. Umecky, T. Aizawa, Y. Ikushima, Electrochemistry 72 (2004) 703.

15 M. Demizu, M. Terazima, Y. Kimura, Analytical Sciences 24 (2008) 1329.

${ }^{16}$ M. Demizu, M. Terazima, M. Harada, K. Saijo, Y. Kimura, Bull. Chem. Soc. Jpn. 84 (2010) 70 .

17 C. P. Fredlake, M. J. Muldoon, S. N. V. K. Aki, T. Welton, J. F. Brennecke, Phys. Chem. Chem. Phys. 6 (2004) 3280.

18 R. Karmakar, A. Samanta, A. J. Phys. Chem. A 106 (2002) 4447. 
19 J. A. Ingram, R. S. Moog, N. Ito, R. Biswas, M. Maroncelli, J. Phys. Chem. B 107 (2003) 5926.

${ }^{20}$ S. Arzhantsev, N. Ito, M. Heitz, M. Maroncelli, Chem. Phys. Lett. 381 (2003) 278.

${ }^{21}$ N. Ito, S. Arzhantsev, M. Heitz, M. Maroncelli, J. Phys. Chem. B 108 (2004) 5771.

22 R. Karmakar, A. Samanta, J. Phys. Chem. A 107 (2003) 7340.

23 P. K. Mandal, A. Samanta, J. Phys. Chem. B 109 (2005) 15172.

${ }^{24}$ D. Seth, A. Chakraborty, P. Setua, N. Sarkar, J. Phys. Chem. B 111 (2007) 4781.

25 B. Lang, G. Angulo, E.Vauthey, J. Phys. Chem. A 110 (2006) 7028.

26 S. Arzhantsev, H. Jin, G. A. Baker, M. Maroncelli, J. Phys. Chem. B 111 (2007) 4978.

${ }^{27}$ H. Jin, G. A. Baker, S. Arzahantsev, J. Dong, M. Maroncelli, J. Phys. Chem. B 111 (2007) 7291.

28 A. Paul, A. Samanta, J. Phys. Chem. B 111 (2007) 4724.

${ }^{29}$ Y. Kimura, M. Fukuda, K. Suda, M. Terazima, J. Phys. Chem. B 114 (2010) 11847.

30 Y. Shim, M. Y. Choi, H. Kim, J. Chem. Phys. 122 (2005) 044511.

31 H. K. Kashyap, R. Biswas, J. Phys. Chem. B 112 (2008) 12431.

${ }^{32}$ H. K. Kashyap, R. Biswas, J. Phys. Chem. B 114 (2010) 254.

${ }^{33}$ H. K. Kashyap, R. Biswas, J. Phys. Chem. B 114 (2010) 16811.

${ }^{34}$ Y. Kimura, Y. Yamamoto, H. Fujiwara, M. Terazima, J. Chem. Phys. 123 (2005) 054512.

35 Z. Liu, W. Wu, B. Han, Z. Dong, G. Zhao, J. Wang, T. Jiang, G. Yang, Chem. Eur. J. 9 (2003) 3897.

${ }^{36}$ H. Tokuda, K. Hayamizu, K. Ishii, M. A. B. H. Susan, M. Watanabe, J. Phys. Chem. B 108 (2004) 16593.

37 K. R. Harris, L. A. Woolf, M. Kanakubo, J. Chem. Eng. Data 50 (2005) 1777.

38 T. Yamaguchi, S. Miyake, S. Koda, J. Phys. Chem. B 114 (2010) 8126. 
Table 1 Parameters obtained by the fit of the fluorescence peak shift to Eq. (2) for $[\mathrm{BMIm}]\left[\mathrm{NTf}_{2}\right]$ together with the mole fraction of $\mathrm{CO}_{2}$ taken from the literature and absorption peak maximum. The value of $\beta$ is fixed to 0.50 .

\begin{tabular}{ccccccccc}
\hline $\mathrm{P} / \mathrm{MPa}$ & $\mathrm{X}_{\mathrm{CO} 2}$ & $\begin{array}{c}v_{\mathrm{abs}} / \\
10^{3} \mathrm{~cm}^{-1}\end{array}$ & $\begin{array}{c}v_{\infty} / \\
10^{3} \mathrm{~cm}^{-1}\end{array}$ & $\begin{array}{c}\Delta v_{1} / \\
10^{3} \mathrm{~cm}^{-1}\end{array}$ & $\tau_{1} / \mathrm{ps}$ & $\begin{array}{c}\Delta v_{2} / \\
10^{3} \mathrm{~cm}^{-1}\end{array}$ & $\tau_{2} / \mathrm{ps}$ & $\left\langle\tau_{\mathrm{S}}\right\rangle / \mathrm{ps}$ \\
\hline 0.1 & 0 & 23.58 & 18.68 & 0.53 & 0.6 & 1.64 & 58 & 116 \\
3 & 0.42 & 23.61 & 18.76 & 0.44 & 0.6 & 1.63 & 23 & 46 \\
6 & 0.62 & 23.65 & 18.79 & 0.42 & 0.8 & 1.71 & 15 & 30 \\
9 & 0.71 & 23.65 & 18.86 & 0.41 & 0.7 & 1.70 & 12 & 24 \\
14 & 0.77 & 23.63 & 18.86 & 0.60 & 0.8 & 1.71 & 15 & 30 \\
20 & - & 23.61 & 18.97 & 0.57 & 0.8 & 1.72 & 18 & 36 \\
\hline
\end{tabular}


Table 2 Parameters obtained by the fit of the fluorescence peak shift to Eq. (2) for $[\mathrm{BMIm}]\left[\mathrm{PF}_{6}\right]$ together with the mole fraction of $\mathrm{CO}_{2}$ taken from the literature and absorption peak maximum. The value of $\beta$ is fixed to 0.55 .

\begin{tabular}{ccccccccc}
\hline $\mathrm{P} / \mathrm{MPa}$ & $\mathrm{X}_{\mathrm{CO} 2}$ & $\begin{array}{c}v_{\mathrm{abs}} / \\
10^{3} \mathrm{~cm}^{-1}\end{array}$ & $\begin{array}{c}v_{\infty} / \\
10^{3} \mathrm{~cm}^{-1}\end{array}$ & $\begin{array}{c}\Delta \nu_{1} / \\
10^{3} \mathrm{~cm}^{-1}\end{array}$ & $\tau_{1} / \mathrm{ps}$ & $\begin{array}{c}\Delta \nu_{2} / \\
10^{3} \mathrm{~cm}^{-1}\end{array}$ & $\tau_{2} / \mathrm{ps}$ & $\left\langle\tau_{\mathrm{S}}\right\rangle / \mathrm{ps}$ \\
\hline 0.1 & 0 & 23.52 & 18.54 & 0.58 & 0.5 & 1.25 & 190 & 323 \\
1.5 & 0.2 & 23.52 & 18.44 & 0.58 & 0.6 & 1.33 & 117 & 197 \\
3 & 0.34 & 23.52 & 18.46 & 0.63 & 0.6 & 1.36 & 65 & 111 \\
6 & 0.51 & 23.52 & 18.53 & 0.72 & 0.5 & 1.34 & 35 & 60 \\
9 & 0.6 & 23.54 & 18.56 & 0.73 & 0.6 & 1.38 & 28 & 48 \\
13 & 0.65 & 23.53 & 18.56 & 0.65 & 0.5 & 1.31 & 31 & 53 \\
\hline
\end{tabular}


Scheme 1 Structures of molecules used in this work.

Figure 1. Time resolved fluorescence spectra of $\mathrm{C} 153$ in the $\mathrm{CO}_{2}$ mixture of $[\mathrm{BMIm}]\left[\mathrm{PF}_{6}\right]$ at $9 \mathrm{MPa}$ and $40^{\circ} \mathrm{C}$. The data obtained by the Kerr gate method are shown until $180 \mathrm{ps}$, and the data for the longer delay are obtained by the streak camera. The spectrum at different delay time is normalized by the maximum intensity, and is shown with a different offset value for the clarity. The solid lines are the results of the fit to the log-normal function. A sharp peak observed for the spectrum at zero delay time is the Raman signal from the solvent.

Figure 2. Examples of the time profiles of the fluorescence peak shift of $\mathrm{C} 153$ in the $\mathrm{CO}_{2}$ mixtures of $[\mathrm{BMIm}]\left[\mathrm{PF}_{6}\right]$ and $[\mathrm{BMIm}]\left[\mathrm{NTf}_{2}\right]$ at different pressures and $40{ }^{\circ} \mathrm{C}$, respectively. The horizontal scale is logarithmic. The solid lines represent the fit to Eq. (2).

Figure 3. Pressure dependence of the average relaxation time in the $\mathrm{CO}_{2}$ mixtures of $[\mathrm{BMIm}]\left[\mathrm{PF}_{6}\right]$ and $[\mathrm{BMIm}]\left[\mathrm{NTf}_{2}\right]$ at $40{ }^{\circ} \mathrm{C}$, respectively. The vertical scale is logarithmic.

Figure 4. Comparison of the average solvation time of C153 in different RTILs reported ref. 27 with those in this work. 
Figure 5. Comparison of the dependence of the average solvation time of C153 on the molar fraction of $\mathrm{CO}_{2}$ with that of the inverse of the translational diffusion coefficient of DPCP under the same experimental conditions. 
Scheme 1 Y. Kimura et al.<smiles>O=c1cc(C(F)(F)F)c2cc3c4c(c2oc1=O)CCCN4CCC3</smiles><smiles></smiles><smiles>O=S(=O)([N-]S(=O)(=O)C(F)(F)F)C(F)(F)F</smiles><smiles>F[P-](F)(F)(F)(F)F</smiles> 
Figure 1 Y. Kimura et al.

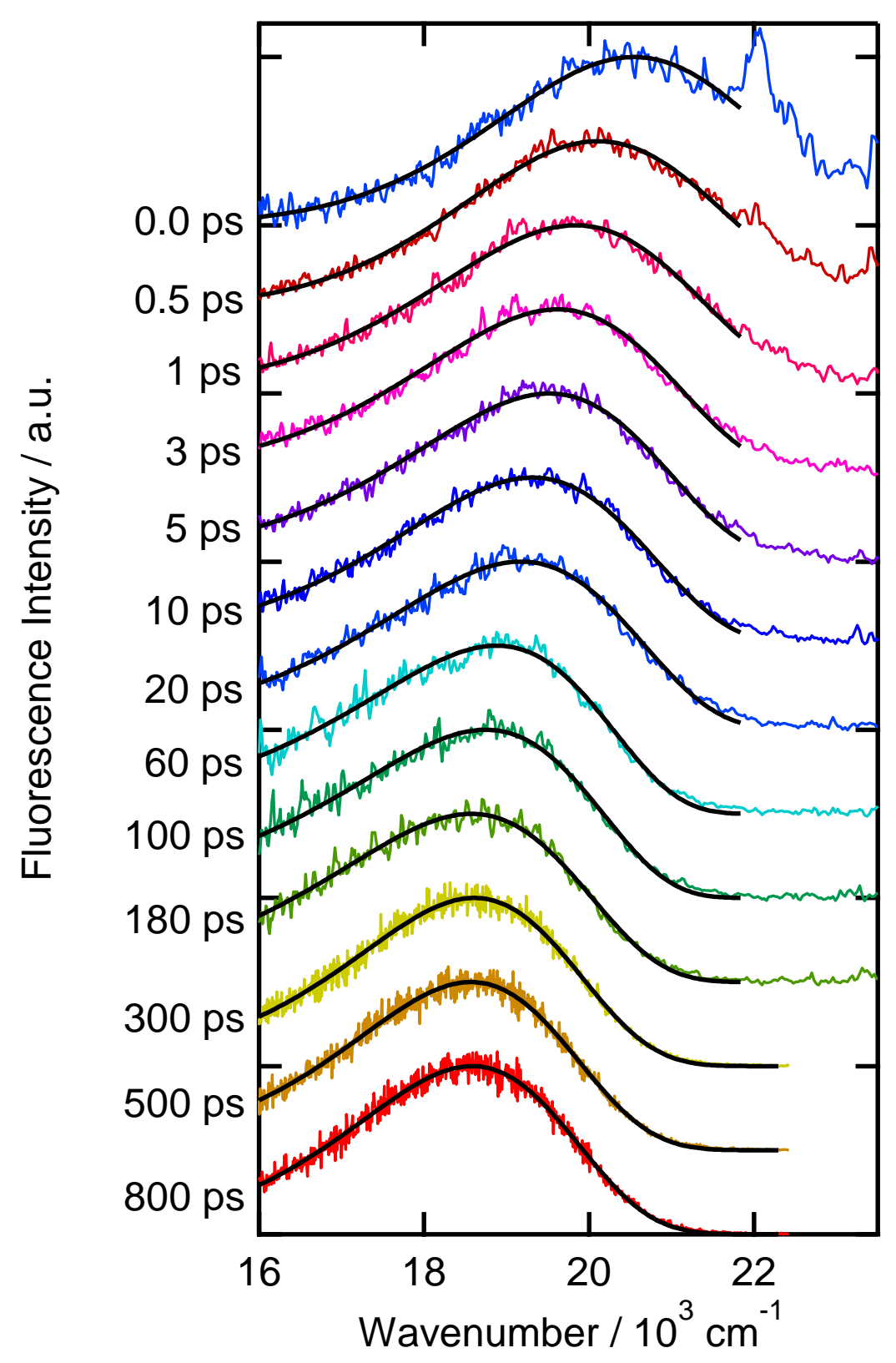


Figure 2 Y. Kimura et al.,
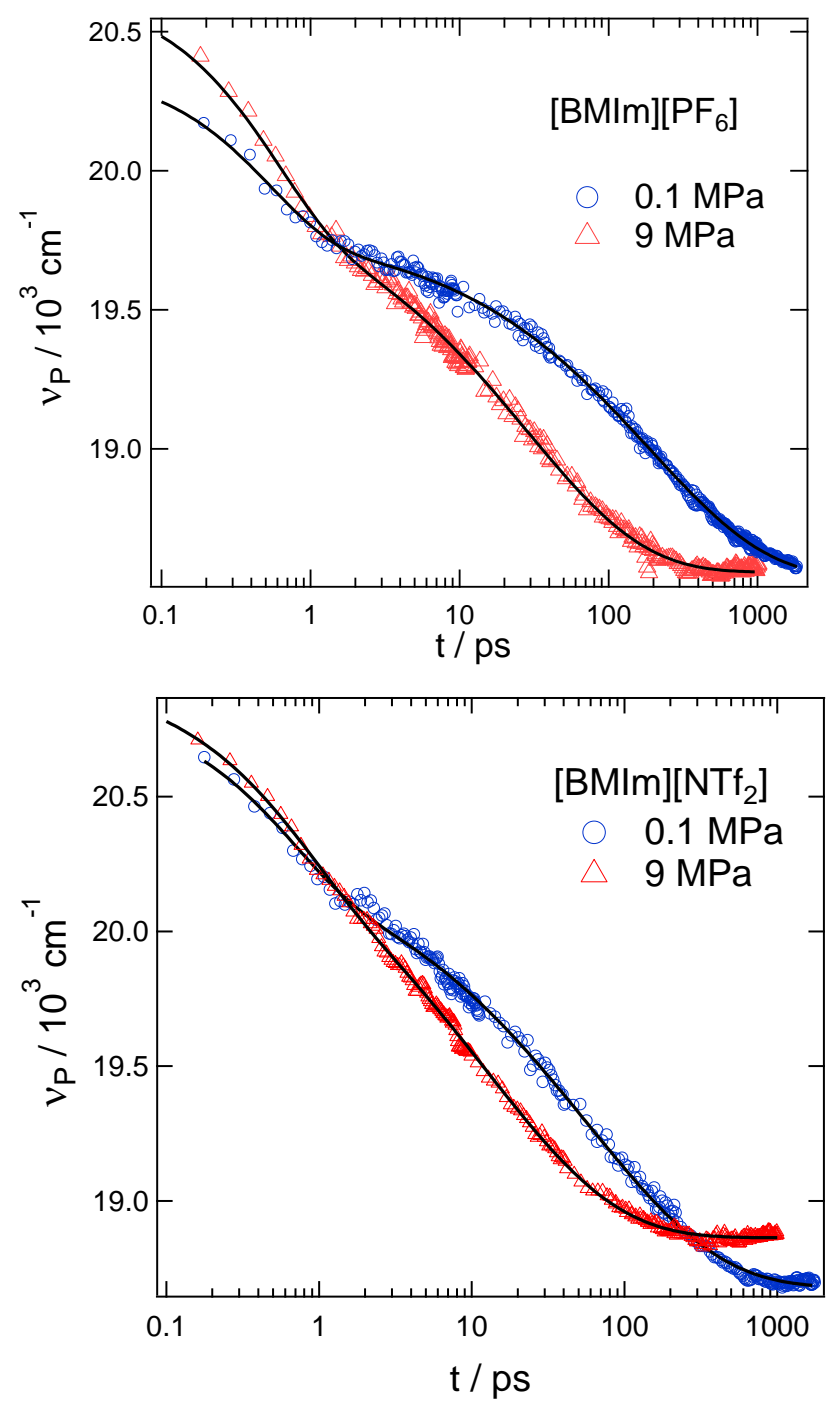
Figure 3. Y. Kimura et al.

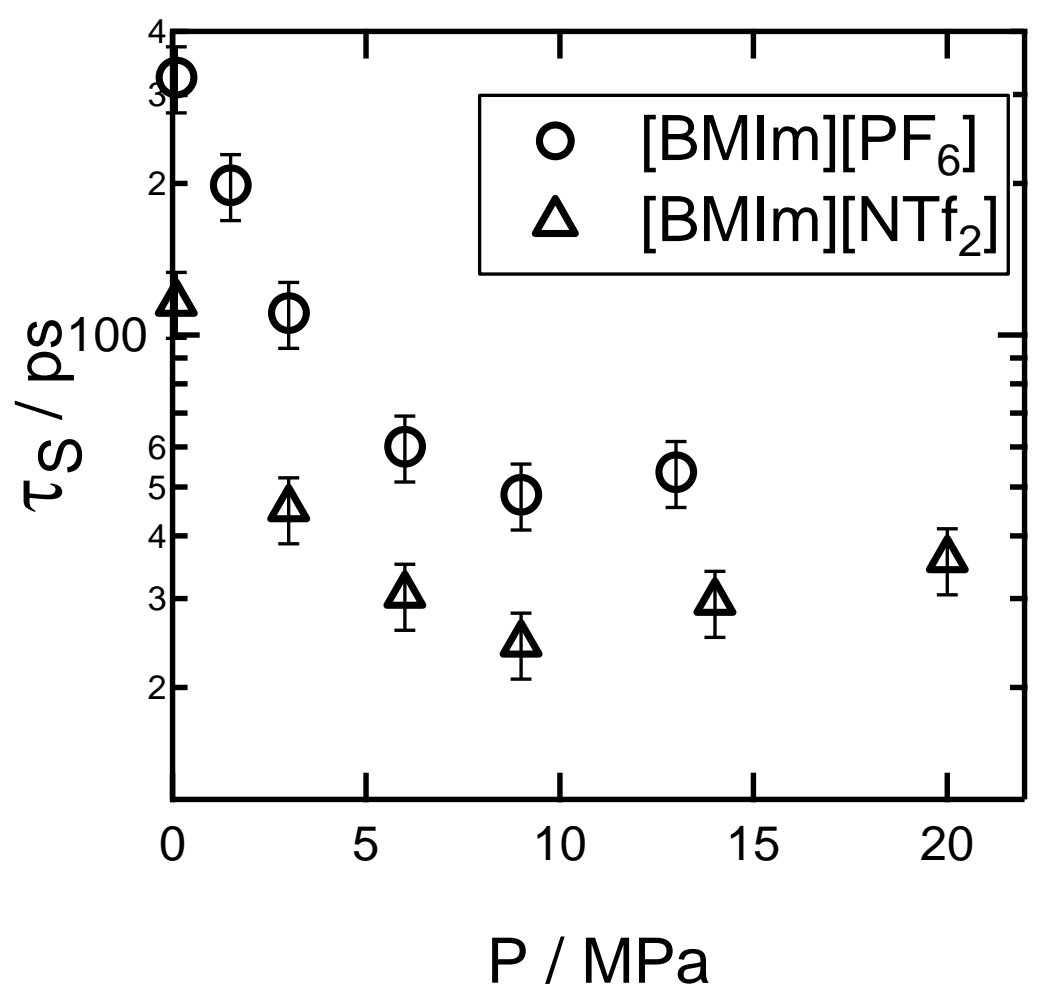


Figure 4. Y. Kimuea et al.

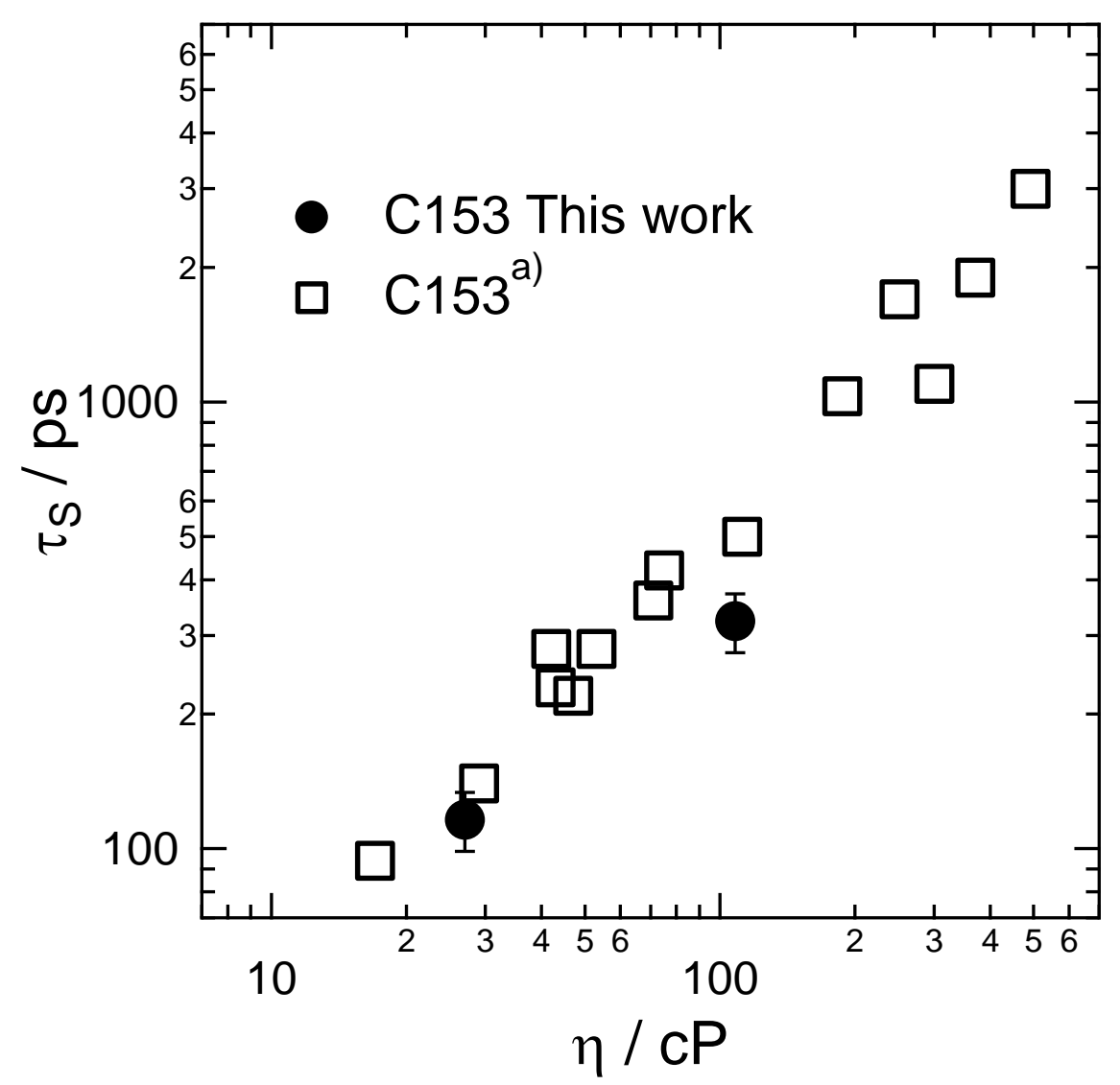


Figure 5. Y. Kimuea et al.
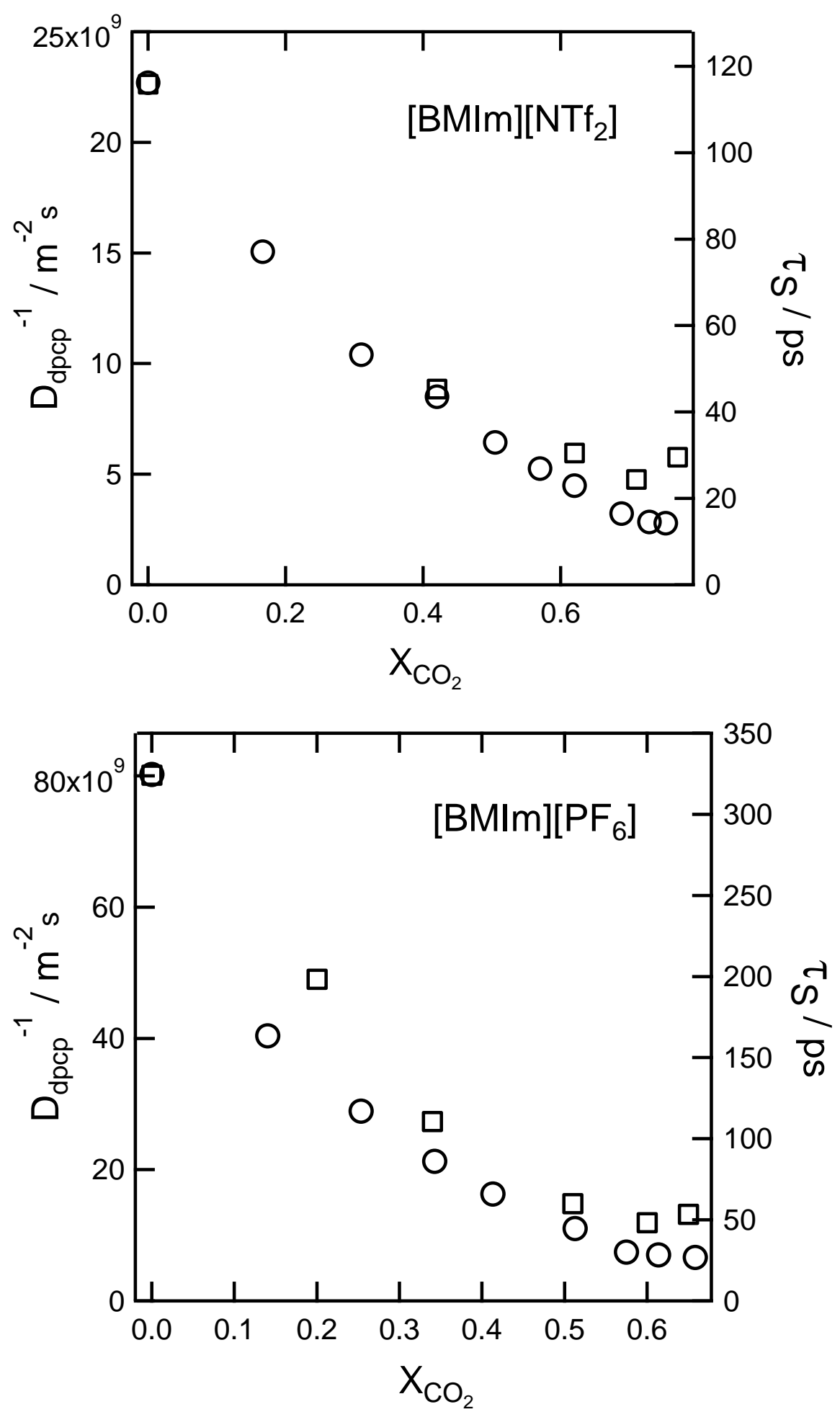